\title{
Early Sexual Debut and Associated Factors among High School Adolescents in Legehida District, Amhara Regional State, Ethiopia
}

\author{
Wassachew Ashebir Kebede* and Belete Yimer Ayele \\ Department of Public Health, Debre Markos University, Ethiopia
}

*Corresponding author: Wassachew Ashebir Kebede, College of Medicine and Health Science, Department of public health, Debre Markos University, Ethiopia.

Submission: 眥 April 13, 2018; Published: 眥 July 23, 2018

\begin{abstract}
Introduction: Adolescents are engaging in sexual risk-taking behaviors at an earlier age, often before they are developmentally ready to deal with the potential outcomes. The main objective of this research was to determine the level of early sexual debut and associated factors among high school adolescents in Legehida district between 15 February and 15 March/2015.

Methods: A quantitative school based cross-sectional study was employed among 406 randomly selected high school adolescents in Legehida district. Data was collected using a structured self-administrated questionnaire adapted from sexual and reproductive health questionnaires of World Health Organization. Data was analyzed using multivariate logistic regression with odds ratio along with the $95 \% \mathrm{CI}$ to identify the predictors of early sexual debut.

Results: About 27.6\% (95\% CI=23.8-34.3) of respondents were initiated sex before the age of 18 years. The mean age at first sexual intercourse was 15 ( \pm 1.6$)$ years. Living alone during high school education (AOR=9.6, 95\%CI=6.3-28.8), having pocket money per month (AOR=2.34; 95\% $\mathrm{CI}=1.40-3.91)$, having a boy/girl friend ( $\mathrm{AOR}=2.53$; 95\% $\mathrm{CI}=1.51-4.25)$ and watching pornographic movies $(\mathrm{AOR}=6.65 ; 95 \% \mathrm{CI}=2.35-18.88)$ were found to be significantly associated factors with early sexual debut.
\end{abstract}

Conclusion: A large proportion of high school adolescents were engaged in early sexual debut. Therefore, a targeted risk reduction intervention should be taken by adolescent themselves, their parents, school communities and all other concerned bodies of the district.

Keywords: Sexual debut; Adolescents; High school; Predictors; HIV/AIDS; Ethiopia

\section{Introduction}

Adolescence is the time of transition from childhood to adulthood during which young people experience changes following puberty. Sexual and reproductive growth and development is one of the remarkable changes during this period [1,2]. Initiating sexual activity is a natural transition made by nearly all human beings. Several reasons for debut of sexual intercourse were mentioned including, but not limited to, falling in love, desire to practice sexual intercourse, peer pressure, and to get money or gifts [35]. Nevertheless, it is not the occurrence of this transition, but the timing and the circumstances under which it occurs that matter [6].

Adolescents are engaging in sexual risk-taking behaviors at an earlier age, often before they are developmentally ready to deal with the potential outcomes [7]; early age sexual activity among adolescents is disproportionately high and increasing in Sub-Saharan Africa [4]. According to Ethiopian Demographic and Health Survey (EDHS) 2011 report, among women age 25-49 years, $29 \%$ first had sexual intercourse before age 15.5 [8]. Data from the 2005 Youth Risk Behavior Surveillance Survey (YRBS) indicate that $6.2 \%$ of high school students engage in sex before the age of thirteen [9]. Studies of sexual behavior among high school students have also established that some adolescents experience sexual intercourse prior to entering high school. According to nationally representative 2009 YRBS data, 32\% of ninth graders had initiated sexual intercourse, $8 \%$ before the age of 13 [10].

Early age sexual debut occurring during an HIV/AIDS pandemic that disproportionately affects adolescents and young adults $[11,12]$. High school adolescents who begin early sexual activity are at increased risk to have high-risk sex or multiple partners, engaging in frequent sexual intercourse, use alcohol or drugs before sex, and are less likely to use condoms. Consequently, these groups of population are frequently exposed to various health, social and economic problems of sexual and reproductive health risks including are at greater risk of experiencing depression, contracting STIs including HIV/AIDS, unwanted pregnancy and 
unsafe abortion and are less likely to reach post-secondary levels of education $[8,13-15]$.

According to a recent estimate, one out of five adolescents has at least one serious health problems. Over $60 \%$ of STI and HIV/ AIDS cases reported yearly occur under the age of 24 with one fourth being 15-19 years [16]. As evidenced from the Demographic and Health Survey report, youths are particularly vulnerable to HIV in Ethiopia with a prevalence of $2.4 \%$ and are the key to the future course of the HIV/AIDS epidemic [8].

There is no one factor that explains most high school adolescents' sexual or reproductive health behavior $[17,18]$. As evidenced by different literatures, the timing of sexual debut among high school adolescents is influenced by a wide range of interrelated factors including socio demographic, environmental and individual factors $[15,19]$. A significant number of adolescents including high school students are involved in sexual activities at an early age as they often face enormous pressure, especially from peers, exposed to unlicensed erotic video films and the desire for economic gain [11]. Furthermore, adolescents who are involved in delinquent activities, or who have higher levels of externalizing behaviors are at increased risk for early sex $[20,21]$.

In Ethiopia, adolescents have been given higher priority in the prevention and control of HIV/AIDS because most new infections are occurring among them so that delaying sexual debut is the pillar of HIV/STIs prevention among adolescents [22,23]. Adolescent girls in Ethiopia are more vulnerable to HIV than boys because of, on top of biological vulnerability, socio-cultural factors including, early age at sexual debut, early marriage, sexual abuse and violence such as rape and abduction [8]. As well as, they are unlikely to have had any training or experience in sexual negotiation skills, and are especially vulnerable in situations with older men where age, wealth, physical strength and other power dynamics put them at a disadvantage services [16].

The 2005 EDHS revealed that higher-risk sexual practices among both women and men were most prevalent in urban areas, among those with secondary school education or higher, and among those in the highest wealth quintile [8]. It was also reported that in Ethiopia risk of women having HIV infection is particularly exacerbated by early sexual debut, lack of comprehensive HIV/ AIDS knowledge and lack of access to health care services. The young age of students, long periods of physical stay in the educational environment and emotional contacts within school communities are reported to increase the collective vulnerability of these communities to HIV/AIDS [24]. Adolescents have limited knowledge about sexual and reproductive health and know little about the natural process of puberty. Most information for their little knowledge comes from peers of the same sex who may themselves lack adequate information or are incorrectly informed [3].

However, addressing high school adolescents as a separate target group with their own needs is a relatively recent practice, especially in developing countries [4]. The high rates of unintended pregnancy, abortion, HIV/AIDS and other sexually transmitted infections (STIs), among others, in teenagers makes it imperative to understand and assess the factors that are associated with early sexual début. Studies conducted so far on adolescent early sexual debut and factors related to it in Ethiopia, particularly among school adolescents were few in number, most of the studies were about premarital sexual practice and some of the studies were old which may not show the present reality. An understanding of the causes and consequences of early debut of reproductive-related behaviors is crucial for designing and implementing effective interventions targeting adolescents. Therefore, this study was conducted to assess the level of early sexual debut and associated factors among high school adolescents in Legehida district. Thus, the findings from this study will inform policy makers, local program managers, community, parents and adolescents to take interventions to reduce the sexual risk of high school adolescents.

\section{Methods}

Study area, design and population. An institution based crosssectional study was employed among high school adolescents in Legehida district, Amhara Regional State, Ethiopia from February15/2015 to March 15/2015. The district is one of 22 districts with 1 urban and 15 rural kebeles in South Wollo Zone. Woinmba is its capital city and located 103KMs from Dessie (the capital city of South Wollo Zone), 600Kms from Bahr-Dar (the capital city of Amhara National Regional State) and 503Kms from Addis-Ababa (the capital city of Ethiopia). According to Legehida district health office report, the total population of the district, in the year 2014, was estimated to be 48,000 (26,000 males and 22,000 females). The health system of the district consisted of 4 health centers, 15 health posts, and 1 private drug venders. There are 2 high schools in the district, Almazbum which is located in urban kebele and Shikif high school in the rural kebele of the district. These high schools are providing educational services for a total of 1721 students (male, 1048 and females, 673) from grade 9 to grade 10. Students, whose parents reside in rural areas, live away from their parents in rented houses alone or with other peers in the area [25].

\section{Sample size and sampling procedure}

A total of 409 study subjects were estimated using early sexual debut of $41 \%$, confidence interval of $95 \%$; margin of error of $5 \%$ and none response rate of $10 \%$. The Almazbum and Shikif high schools in the district were used. The number of sampled students proportional to their population size were calculated from each school and divided in to grade $9^{\text {th }}$ and $10^{\text {th }}$. Half of randomly selected sections from each school (11 from Almazbum and 6 from Shikif high schools) were included in the study. A sampling frame was the lists of high school students in the 17 sections. Sample sections and students from each section were selected using simple random sampling technique.

\section{Data collection and measurements procedures}

A self-administrated questionnaire adapted from the sexual and reproductive health questionnaires of WHO were used for 
the data collection. The questionnaires was first be prepared in English and translated in to local language and back to English to keep consistency of the questionnaires. Data was collected by four thoroughly trained grade twelve completed data collectors and supervised by two primary school teachers and the principal investigator who were able to speak and write local languages. A pre- test was conducted in Woreillu high school on $5 \%$ of the total sample size which was not included in the main study. The adapted questionnaire was modified, contextualized to the local situation and the research objectives. Information on socio- demographic characteristics; sexual behavior, non-sexual behavior, knowledge on sexual and reproductive issues, attitude toward sexual and reproductive issues, adolescent-parent communication on sexual and reproductive issues were assessed using a self-administrated questionnaires that were handed out to the students who consented to participate in the study in separate rooms during break period. The study information sheet was attached with the questionnaires.

\section{Adolescents}

students who are between the ages of 10-19 years old [26]; early sexual debut: defined as having sexual intercourse before the age of 18 years and no if participants reported either initiated sex after aged 18 or never had sex; parental monitoring/supervision: an adolescent is said to have parental monitoring if he/she responds yes to the question 'do your parents know where you are, who you are with and what you do in your free time or where you are not at home?'; comprehensive knowledge on HIV: ability to identify the two important prevention ways (being faithful and condom use), being aware that a healthy-looking person can have HIV and reject the two locally common misconceptions about HIV transmission (mosquito bite and sharing food); attitude toward sexual issues: An adolescent is said to have positive attitude if they agree for four and above out of six attitude questions and negative attitude if they disagree for three and less out of six attitude questions; alcohol use: a study participant is considered as ever drinker if he/she responds yes to the question 'Have you ever drunk alcohol in your life?' Then

Table 1: Socio-demographic characteristics of Legehida high school adolescent students, Northeast Ethiopia, 2015 $(n=406)$. follow up questions will be employed to collect information such as drinking in the past one year and frequency of drinking [8].

\section{Statistical Analysis}

Data were double entered and cleaned in EPI data software version 3.1. The entered data were exported and analyzed using SPSS version 21. Bivariate and multivariate logistic regression analysis with odds ratio along with the confidence interval of $95 \%$ were used. P-value $<0.05$ were considered for statistical significant. The bivariate at $(\mathrm{P}<0.2)$ were included in the multivariable logistic regression to control for confounding.

\section{Ethical Consideration}

Officially written approval letter from Haramaya University Institutional Research Ethics and Review Committee (IRERC) was obtained prior to the study. Accordingly, administrative bodies of Legehida district were communicated for their permission. Before informed consent obtained, clear and adequate information was provided to the respondents about the research and their right of participation including their right to decline participation any time they feel to do so. For adolescents who were less than 18 years, the four data collectors went to home of the parents/guardians and obtained their signed consent before the time of data collections and assent was also obtained from the students as well. Privacy and confidentiality were kept in all data collection procedures.

\section{Results}

\section{Socio- demographic characteristics of respondents}

Among the 409 students requested to fill out the selfadministered questionnaire, 406 students responded, making the response rate $99 \%$. From the total respondents, female accounting nearly half 200 (49.3\%). The majority of the respondents (99.5\%) were aged between 15 and 18 years with the mean age of $16.8( \pm 1.1)$ years. Majority of the respondents Muslim in religion (72.9\%) and all of the respondents were Amhara in ethnicity (Table 1).

\begin{tabular}{|c|c|c|c|}
\hline \multirow{2}{*}{ Variable } & Category & Frequency & Percentage (\%) \\
\hline \multirow{2}{*}{ Sex } & Male & 206 & 50.7 \\
\cline { 2 - 4 } & Female & 200 & 49.3 \\
\hline \multirow{2}{*}{ Marital Status } & Single & 368 & 90.6 \\
\hline \multirow{2}{*}{ Religion } & Married & 38 & 2.4 \\
\cline { 2 - 4 } & Orthodox & 110 & 27.1 \\
\cline { 2 - 4 } & Muslim & 296 & 72.9 \\
\hline \multirow{2}{*}{ Grade Level } & Grade 9 & 262 & 34.5 \\
\hline
\end{tabular}




\begin{tabular}{|c|c|c|c|}
\hline \multirow{2}{*}{ Pocket Money From Family per Month } & Yes & 236 & 59 \\
\hline & No & 168 & 41 \\
\hline \multirow{6}{*}{ Living Arrangement } & With Father and mother & 220 & 54.2 \\
\hline & Father only & 32 & 7.9 \\
\hline & Mother only & 38 & 9.4 \\
\hline & With relatives & 42 & 10.3 \\
\hline & With friends/peers & 20 & 4.9 \\
\hline & Alone & 54 & 13.3 \\
\hline \multirow{5}{*}{ Attending Religious Service } & Daily & 162 & 39.9 \\
\hline & At least once per week & 92 & 22.7 \\
\hline & At least once per month & 30 & 7.4 \\
\hline & At least once per year & 54 & 13.3 \\
\hline & Never & 68 & 16.7 \\
\hline \multirow{2}{*}{ Residence of Family } & Rural & 324 & 79.8 \\
\hline & Urban & 82 & 20.2 \\
\hline \multirow{2}{*}{ Educational Level of Father } & Illiterate & 98 & 24.1 \\
\hline & Literate & 208 & 75.9 \\
\hline \multirow{2}{*}{ Educational Level of Mother } & Illiterate & 146 & 36 \\
\hline & Literate & 260 & 64 \\
\hline
\end{tabular}

Sexual activity history and related issues of the who had early sexual practice, the mean age at first sexual respondents intercourse was $(15 \pm 1.6)$ years. Of those who had early sexual

Among adolescents who participated in this study, 112(27.6\%) had first sexual intercourse at less than 18 years. For adolescents debut, forty $(63 \%)$ of respondents were from grade 9 while the remainder were from grade 10.

Table 2: Description of sexual activities, knowledge and attitude about sexual and reproductive health issues and parental relationshis Legehida high school adolescent students, Northeast Ethiopia, 2015 ( $n=406)$.

\begin{tabular}{|c|c|c|c|}
\hline Variables & $\begin{array}{l}\text { Male } \\
\text { n (\%) }\end{array}$ & $\begin{array}{c}\text { Female } \\
\text { n (\%) }\end{array}$ & $\begin{array}{c}\text { Total N } \\
(\%)\end{array}$ \\
\hline \multicolumn{4}{|c|}{ Age at first sex } \\
\hline No sex & $51(35.4)$ & $93(64.6)$ & $144(35.5)$ \\
\hline$<18$ & $58(51.8)$ & $54(48.2)$ & $112(27.6)$ \\
\hline$\geq 18$ & $50(33.3)$ & $100(66.7)$ & $150(36.9)$ \\
\hline \multicolumn{4}{|c|}{ Parent adolescent SRH* communication } \\
\hline Yes & $73(42.7)$ & $124(57.3)$ & $197(48.5)$ \\
\hline No & $88(63.8)$ & 121(36.2)) & $209(51.5)$ \\
\hline \multicolumn{4}{|c|}{ Knowledge of adolescents SRH } \\
\hline
\end{tabular}




\begin{tabular}{|c|c|c|c|}
\hline Good & $100(51.6)$ & $139(48.4)$ & $110(58.8)$ \\
\hline Poor & $57(41.2)$ & $167(41.1)$ \\
\hline \multicolumn{2}{|c|}{ Currently have a boy-/girlfriend } \\
\hline \multicolumn{5}{|c|}{ Viewing pornography material } \\
\hline Yes & $74(59)$ & $109(41)$ & $183(45.1)$ \\
\hline No & $77(37)$ & $146(63)$ & $223(54.9)$ \\
\hline Yes & $87(72)$ & $107(28)$ & $194(47.8)$ \\
\hline No & $69(30.6)$ & & $212(52.2)$ \\
\hline
\end{tabular}

\section{*Sexual and Reproductive Health}

Regarding the attitude towards sexual and reproductive health issues, $242(59.6 \%)$ of the respondents had negative attitude for this issue. Among the respondents who initiate sex at an earlier age, 51(45.5\%) hasn't had any parental monitoring. More than half of high school adolescent's responded that reproductive health services were given in their school (Table 2).

Factors associated with early sexual debut among Legehida high school adolescent

The results of Bivariate and multivariate analysis between early sexual debut among high school adolescents and selected

Table 3: Factors associated with early sexual debut among legehida high school adolescent students, Northeast Ethiopia, $2015(n=406)$.

\begin{tabular}{|c|c|c|c|c|}
\hline \multirow{2}{*}{ Variables } & \multicolumn{2}{|c|}{ Early Sexual Debut } & \multirow{2}{*}{$\operatorname{COR}(95 \% \mathrm{CI})$} & \multirow{2}{*}{ AOR(95\%CI) } \\
\hline & Yes & No & & \\
\hline \multicolumn{5}{|c|}{ Religion } \\
\hline Orthodox & $27(24.5 \%)$ & $83(75.5 \%)$ & $1.77(1.0-2.60)$ & $1.27(0.7-2.3)$ \\
\hline Muslim & $85(28.7 \%)$ & 211(71.3\%) & 1 & 1 \\
\hline \multicolumn{5}{|c|}{ Pocket Money } \\
\hline Yes & $95(39.9 \%)$ & $143(60.1 \%)$ & $2.79(1.79-4.12)$ & $2.34(1.40-3.9)^{*}$ \\
\hline No & $17(10.1 \%)$ & $151(89.9 \%)$ & 1 & 1 \\
\hline \multicolumn{5}{|c|}{ Living condition } \\
\hline Father and mother & $51(26.8 \%)$ & $168(73.2 \%)$ & 1 & 1 \\
\hline Father only & $7(22.6 \%)$ & $24(77.4 \%)$ & $1.28(0.53-3.10)$ & $1.7(0.60-4.83)$ \\
\hline Mother only & $10(27 \%)$ & $27(73 \%)$ & $1.31(0.57-3.02)$ & $1.67(0.56-4.9)$ \\
\hline With relatives & $3(11.1 \%)$ & $24(88.9 \%)$ & $0.26(0.07-0.98)$ & $0.4(0.08-1.58)$ \\
\hline With friends/peers & $7(17.1 \%)$ & $34(82.9 \%)$ & $0.81(0.35-1.86)$ & $0.96(0.35-2.6)$ \\
\hline Alone & $34(66.7 \%)$ & $17(33.3 \%)$ & 7.3(4.7-11.3) & $9.6(6.3-28.8)^{*}$ \\
\hline \multicolumn{5}{|c|}{ Watching pornography/ week } \\
\hline Once & $56(46.7 \%)$ & $64(53.3 \%)$ & $3.56(2.29-5.80)$ & $2.30(1.29-4.0)^{*}$ \\
\hline Twice & $7(18.9 \%)$ & $30(81.1 \%)$ & $3.86(1.80-7.56)$ & $2.12(0.88-5.1)$ \\
\hline Three times and above & $1(4.2 \%)$ & $23(95.8 \%)$ & $5.3(2.05-12.34)$ & $6.7(2.35-18.8)^{*}$ \\
\hline Never watch & $48(21.3 \%)$ & $177(78.7 \%)$ & 1 & 1 \\
\hline \multicolumn{5}{|c|}{ Alcohol drinking/ week } \\
\hline Once & $33(41.1 \%)$ & $57(58.9 \%)$ & $2.8(1.65-4.37)$ & $1.35(0.7-2.54)$ \\
\hline
\end{tabular}

independent factors are presented in Table 3 below. Accordingly, in the Bivariate analysis; high school adolescents who were drinking alcohol once per week (COR=2.87, 95\%CI; 1.65-4.37) were 2.87 times more likely to practice early sexual debut and those who were drinking alcohol twice and above per week (COR=3.00, 95\%CI; 1.43-5.55) were 3 time more likely to practice early sexual debut than those who never drink alcohol. In addition, adolescents who had positive attitude to sexual issues (COR=1.57, 95\%CI; 1.11-2.48) were 1.57 times more likely to practice early sexual debut than those who had negative attitude to sexual issues. 


\begin{tabular}{|c|c|c|c|c|}
\hline Twice and above & $4(40 \%)$ & $36(60 \%)$ & $3.00(1.43-5.55)$ & $2.2(0.92-5.06)$ \\
\hline Never & $75(34.8 \%)$ & $201(65.2 \%)$ & 1 & 1 \\
\hline \multicolumn{5}{|c|}{ Having a boy/girl friend } \\
\hline Yes & $56(39 \%)$ & $85(61 \%)$ & $3.27(1.14-6.23)$ & $2.5(1.51-4.25)^{*}$ \\
\hline No & $56(32.8 \%)$ & $209(67.2 \%)$ & 1 & 1 \\
\hline \multicolumn{5}{|c|}{ Positive attitude to sexual issues } \\
\hline Yes & $52(31.7 \%)$ & $112(68.3 \%)$ & $1.57(1.11-2.48)$ & $1.3(0.79-2.18)$ \\
\hline No & $60(37.6 \%)$ & $182(62.4 \%)$ & 1 & 1 \\
\hline \multicolumn{5}{|c|}{ Provision of RH services at school } \\
\hline Yes & $73(48.1 \%)$ & $141(51.9 \%)$ & $0.63(0.32-0.95)$ & $1.5(0.6-3.4)$ \\
\hline No & 39 (36.5\%) & $153(63.5 \%)$ & 1 & 1 \\
\hline
\end{tabular}

Key: COR: Crude Odds Ratio; AOR= Adjusted Odds Ratio; CI=Confidence Interval; *Significant at 5\%

In the final model analysis (multivariate analysis), the result indicated that; living alone during high school education, having pocket money per month, having a boy/girlfriend and watching pornographic movies found to be the main significant factors associated with early sexual debut adjusting for all other variables. Thus, high school adolescents who lived alone during high school education were more than nine times more likely to experience early sexual debut compared to those who lived with their both parent(AOR=9.6, 95\%CI=6.3-28.8). Adolescents who get pocket money per month were more than two times more likely to practice early sexual debut than those who didn't receive pocket money from their parent $(\mathrm{AOR}=2.34,95 \% \mathrm{CI}=1.40-3.91)$. Adolescents having a boy/girlfriend were more than two times more likely to experience early sexual debut compared to those who didn't have a boy/girlfriend (AOR=2.53, 95\% CI=1.51-4.25). Similarly, high school adolescents who reported watching pornographic movies were more than six times more likely practice early sexual debut than those who didn't (AOR=6.65, 95\% CI=2.35-18.88) (Table 3).

\section{Discussion}

This study revealed that $27.6 \% \quad(95 \% \quad \mathrm{CI}=23.8-34.3)$ of respondents were involved in early sexual debut. When compared with other studies, the finding of this study is comparable with studies done in Nekemte, Dessie and Shendi Town $[3,12,14]$. But, the finding of this study is relatively lower than them .This difference could be due to the study population [This study assessed the prevalence of early sexual debut among high school students aged 10 to 19 years old, while the other study included only adolescents who are at the age group of 15 to 24 years old]. The other reason could be the number of sample used, the current study assessed adolescents found in two schools, while the others included a large number sample with diverse population. On the contrary, this finding is higher than a study in Nairobi [27]. The variation in the result could be due to the definition of early sexual debut among adolescents, research design and instruments used that varied between settings, cultures and populations.

The median age of first sexual initiation in this study is $15.5( \pm 1.9)$ years for males and $16( \pm 1.5)$ years for females which is comparable with other previous studies in Ethiopia. It is slightly lower than the study done in Gamo Gofa and Dessie Town $[14,23]$.
The difference may be explained by the difference in the study population; as this study involved only high school adolescents within narrow age range (10-19 years) while the others covered a wider area and diverse population, and this study was conducted in a setting that has rural nature compared to others. But the finding of this study is higher than the study in Jamaica [4] and in Transkei in South Africa adolescents [28].

In this study, living condition during high school education was found to be strong predictors of early sexual debut and living alone exposed adolescents to practice sex a early age. This finding was in agreement with the study conducted in Shendi [12]. The most likely explanation is that those who live alone during high school education instead of their biological parent lack familial control and connectedness which can give them to have a sense of freedom to practice what they want. Having pocket money per month was found to be a significant predictor of early sexual debut. In this study, adolescents who get pocket money per month were 2.3 times more likely to start sex early than those who didn't receive pocket money from their parent. The result is consistent with earlier study findings conducted in Nekemte [3]. This may be due to lack of skills to wisely use the pocket money which may be above what was required for subsistence and the opportunity to enter into sexual relationship to satisfy their economic and material needs.

According to the result of this study, frequency of watching pornographic video was significantly associated with early sexual debut .Students who watch pornographic video one or less times a week and three or more times a week were 2.3 and 6.7 times more likely to start early sexual debut respectively than those who never watch. This could be because adolescents who watch pornographic movies may develop unrealistic attitudes about sex, which leads them to engage in sexual practice [27]. A study done in North East Ethiopia also showed that watching pornographic materials at age less than 18 years old was found to be associated with sexual initiation [14]. A study done in Shendi also showed that students who had not seen sex films were less likely to get in to sexual intercourse than those who had seen such film [12]. Ethiopia's increased openness to Western culture has resulted in the influx of pornographic videos, books, and magazines, whose consumers are mostly young and adolescent people. Western pornography often 
preceded sexual initiation and helped the couple to "loosen up" a bit.

However, alcohol drinking was not associated with early sexual debut in this study which contrasts with the result of a study among high school students in Dessie where adolescents drinking alcohol were at higher risk of initiating sex than their counterparts [14]. This might be due to few numbers of respondents who acknowledged alcohol drinking in these study populations. Another explanation for this could be being Muslim for majority of our adolescents which prevent them from drinking, under-reporting of alcohol drinking because of cultural issues or could be due to recall bias.

Sexual debut is more likely among adolescents with a boyfriend or girlfriend, as most adolescent sexual activity occurs within a romantic relationship [29-31]. A study done in Nigeria showed that, high school adolescents who have a boyfriend or girlfriend were more likely to have early sexual debut than those who do not have a boy/girlfriend [4,5]. Similar finding was also observed in this study that adolescents who have a boy/girlfriend are more likely to involve in early sexual debut than those who don't have a boy/girlfriend. This could be due to the pressure from their girl/ boyfriend to have sexual practice. In Ethiopia, a study done in Nekemete town also showed that having a boy/girl friend is one factor which determines to start sexual intercourse at early age [3].

\section{References}

1. Attawell K (2004) Going to scale in Ethiopia: mobilizing youth participation in a National HIV/AIDS program. The Synergy Project, Social \& Scientific Systems, Washington, USA, PR 1. BS/9851.

2 Jennifer C, Wendy C, Adele G, Debra P (2004) Mixed-gender groups, dating and romantic relationships in early adolescence. J Res Adolesc 14(2):185-207.

3. Assefa S, Dessalegn W (2008) Premarital sexual practice among school adolescents in Nekemte Town, East Wollega. Ethiop J Health Dev 22(2): 167-173.

4 Olaniyi JE, Joana DS, Michele R, Inmaculada CA, Laura HB et al. (2012) Debut of heterosexual activity among adolescents in rural Jamaica: the influence of family factors. J Educ Soc Dev 1(2).

5 Ankomah A, Mamman DF, Omoregie G, Anyanti J (2011) Reasons for delaying or engaging in early sexual initiation among adolescents in Nigeria. Adolesc Health Med Ther 2: 75-84.

6 Abebe A, Mitikie G (2009) Perception of high school students towards voluntary HIV counseling and testing, using health belief model in Butajira, SNNPR. Ethiopian Journal of Health Development 23(2).

7. World Health Organization (2013) Special program of research development and research training in human reproductive health (HRP). Promoting health through the life-course, World Bank 64.

8 Central Statistical Agency [Ethiopia], ICF International (2012) Ethiopia demographic and health survey 2011. Central Statistical Agency and ICF International, Maryland, USA.

9. Future of Children, Princeton Brookings (2008) Providing research and analysis to promote effective policies and programs for children. Spring $18(1)$.

10. Danice KE, Steve K, Shari S, James R, Joseph H, et al. (2010) Youth risk behavior surveillance-United States, 2009. Morbidity and Mortality Weekly Report 59(5): 1-142.

11. Okonofua F (2007) New research findings on adolescent reproductive health in Africa. African Journal of Reproductive Health 11(3): 7-9.
12 Alene GD, Wheeler JG, Grosskurth H (2010) Adolescent reproductive health and awareness of HIV among rural high school students, North Western Ethiopia. Ethiop J Health Dev 16(1): 57-68.

13. Ethiopian Public Health Association (2008) Adolescent reproductive health task force, adolescent reproductive health global and national initiatives and lesson learned.

14. Fekadu M, Alemayehu W (2009) Age at sexual debut and factors associated with it among youths in North East Ethiopia. Ethiop J Health Dev 23(2): 154-162.

15. Mitike M, Yemane B, Bernt L (2008) Traditional values of virginity and sexual behavior in rural Ethiopian youth: results from a cross-sectional study. BMC Pub Health 8(9).

16. Berhane Y, Yared M, Eleni S, Lawrence G, David W (2008) HIV/AIDS in Ethiopia: an epidemiological synthesis. The World Bank 1: 27-109.

17. Blum, Robert W (2015) Risk and protective factors affecting adolescents Reproductive Health in Developing countries. Department Of Family Health, WHO, Switzerland.

18. Okonta P, Oseji M (2009) Relationship between knowledge of HIV/AIDS and sexual behavior among in-school adolescents in Delta State, Nigeria. Niger J Clin Pract 9(1): 37-39.

19. Adamu R, Mulatu MS, Haile SI (2003) Patterns and correlates of sexual debut, sexual risk behaviors, and condom use among secondary schools in Ethiopia. Ethiop Med J 41(2): 163-177.

20. Longmore MA, Eng AL, Giordano PC, Manning W D (2009) Parenting and adolescents' sexual debut. J Marriage Fam 71(4): 969-982.

21. Price MN, Hyde J (2009) When two isn't better than one: Predictors of early sexual activity in adolescence using a cumulative risk model. J Youth Adolesc 38(8): 1059-1071.

22. National AIDS Prevention and Control Council (2000) National HIV/aids control program [in Amharic], National AIDS Prevention and Control Council, Addis Ababa, Ethiopia.

23. Maria W (2007) Sexual behavior, knowledge and awareness of related reproductive health issues among single youth in Ethiopia. African Journal of Reproductive Health 11(1): 14-21.

24. Emebet T, Debebe S, Deresse D (2014) Prevalence, associated risk factors and consequences of premarital sex among female students in aletawondohigh school, sidama zone, Ethiopia. J Public Health Epidemiol 6(7): 216-222.

25. Legehida district health and education office report (2014) Legehida, Ethiopia.

26. WHO (2009) HIV/AIDS, JUNPO, report on the global AIDS epidemic. World Health Organization, Switzerland.

27. Kabiru CW, Orpinas P (2009) Factors associated with sexual activity among high-school students in Nairobi, Kenya. J Adolesc 32(4): 10231039.

28. Anochie IC, Ikpeme EE (2001) Prevalence of sexual activity and outcome among female secondary school students in Port Harcourt, Nigeria. Afr J Reprod Health 5(2): 63-67.

29. Matin BV, Kirby DB, Hudes ES, Coyle KK, Gómez CA (2012) Boyfriends, girlfriends and teenagers' risk of sexual involvement. Perspect Sex Reprod Health 38(2): 76-83.

30. Giordano PC, Manning WD, Longmore MA (2006) Adolescent romantic relationships: an emerging portrait of their nature and developmental significance. In: Crouter AC, Booth A (Eds.), Romance and Sex in Adolescence and Emerging Adulthood. Lawrence Erlbaum Associates, Mahwah, USA, pp. 127-150.

31. Lemessa 0, Yemane B, Alemayehu W (2012) Pre-marital sexual debut and its associated factors among in-school adolescents in Eastern Ethiopia. BMC Public Health 12(37). 
Creative Commons Attribution 4.0 International License

For possible submissions Click Here

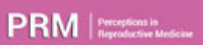 \\ Perceptions in Reproductive Medicine}

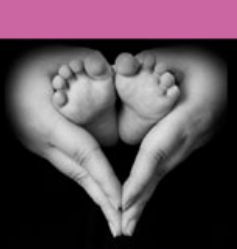

\section{Benefits of Publishing with us}

- High-level peer review and editorial services

- Freely accessible online immediately upon publication

- Authors retain the copyright to their work

- Licensing it under a Creative Commons license

- Visibility through different online platforms 